\title{
UN AGRADECIMIENTO Y TRES APOLOGÍAS: ERROR, REFLEXIÓN Y PREGUNTA*
}

\author{
An appreciation and three apologies: \\ error, reflection and question
}

\author{
Fredie Didier Jr.** \\ Universidad Federal de Bahia
}

Recepción: 09/10/2015

Aceptación: 29/4/2016

\section{Resumen}

El expositor da cuenta de su ascenso en su carrera como profesor universitario, donde - en un primer momento- sus enseñanzas tenían un público local, luego, - con ayuda de la tecnología- ese espacio fue nacional, para de allí traspasar las fronteras de su país natal y llegar al Perú. Asimismo, reflexiona sobre el papel crítico que debe asumir el estudiante universitario de la carrera de Derecho.

Palabras clave: Teoría del derecho; derecho procesal; reflexión; ética.

\section{Abstract}

The exponent realizes his promotion in his career as a university professor, where -in a first moment- his teachings had a local audience, then - with the help of technology - that space was national. Finally, he crossed borders of his native country and got to Peru. Likewise he also reflects on the critical role that must assume a college law student.

Keywords: Theory of law; Procedural law; reflection; ethics.

* Discurso pronunciado en portugués el 4 de septiembre de 2015 en la ciudad de Huancayo, Perú, por el profesor Dr. Fredie Didier Jr., con motivo de su condecoración como Profesor Honorario por la Universidad Continental. Traducción de Renzo Cavani.

** Doctor por la Pontificia Universidad Católica de São Paulo. Profesor en la Universidad Federal de Bahía. Integrante de la International Association of Procedural Law. 
Señor doctor Armando Prieto, Secretario General de la Universidad Continental

Señor doctor William Rodríguez, decano de la Facultad de Derecho de la Universidad Continental

Señora doctora Verónica Marrache, directora de la carrera de Derecho de la Universidad Continental

Buenas noches

\section{EL AGRADECIMIENTO}

Siempre quise ser profesor.

La memoria de este deseo mío remonta a mi adolescencia. Pero yo pensaba en ser profesor en mi ciudad, Salvador de Bahía, en Brasil. Cuando me volví profesor universitario, realicé ese sueño: me había vuelto un profesor local.

Algún tiempo después, por una de esas circunstancias de la vida, con la ayuda de los recursos tecnológicos actuales, me volví profesor nacional. Mis clases pasaron a ser transmitidas por satélite para todo el territorio brasileño. Mis alumnos venían desde la región amazónica a las pampas gauchas; del sertão nordestino al Planalto Central, en Brasilia'; de Minas Gerais a las playas de Río de Janeiro. Pasé a dar clases para veinte mil personas por año. Jamás imaginé que eso podría ocurrir y, por ello, jamás me había preparado para eso. Mi proyecto de vida había alcanzado un nivel hasta entonces insospechado. Y yo ya estaba bastante satisfecho con todo eso.

Mis clases y mis escritos pasaban a ser consultados por innumerables brasileños, de todos los rincones, no solo de mi tierra natal.

Cuando recibí el comunicado que la Universidad Continental, de Huancayo, en Perú, me concedería el título de Profesor Honorario, el asombro fue inevitable: yo me volvería un profesor internacional.

De alguna manera, mis clases y mis escritos atravesaron el continente y llegaron al Perú: estaba siendo escuchado y leído en un país extranjero,

1 [Nota del traductor]: El sertão es una vasta región semiárida en el Nordeste brasileño, de clima tropical y bajas precipitaciones, que forma parte de una planicie muy extensa (Planalto o meseta) que, a su vez, cubre gran parte de Brasil. Planalto central —o macizo central一, por tanto, es la región central de la meseta, en donde se ubica, entre otras ciudades, la capital federal: Brasilia. 
y existían personas a quienes les agradaba. Sin saberlo $-y$, por ello, sin quererlo_ seguí la máxima de Tolstoi: «si quieres ser universal, habla sobre tu aldea».

Existe un proverbio sueco que me conmueve sobremanera: «The afternoon knows that the morning never suspected».

A los 41 años, la tarde de mi vida me reservó algo que la mañana jamás sospechara.

No existe cómo agradecer ese homenaje.

Muchas gracias, muchas gracias, muchas gracias...

\section{UNA PALABRA A MIS COLEGAS PROFESORES Y JURISTAS PERUANOS: LA APOLOGÍA DEL ERROR}

Quisiera aprovechar este momento para compartir con mis colegas profesores que estamos viviendo una nueva fase de la ciencia del derecho procesal y, más específicamente, de la ciencia jurídica latinoamericana.

La ciencia del derecho procesal debe ser reconstruida. Sus conceptos fundamentales fueron formulados hace cien años por los alemanes e italianos; ellos se basaron en la teoría del derecho de fines del siglo XIX. El siglo XX fue dedicado al desarrollo de esos conceptos y al estudio del proceso en otras dimensiones, como la política y la social.

Sucede que la teoría del derecho del siglo XXI, en todas sus cuatro grandes divisiones (teoría de la norma, teoría del ordenamiento, teoría de la interpretación y teoría del hecho jurídico), pasó por tantas y tan profundas transformaciones, que ha llegado la hora de reconstruir también los pilares conceptuales de la ciencia del proceso. La distinción entre texto y norma, la ampliación del uso de las cláusulas generales, la teoría de los derechos fundamentales, la fuerza normativa de la Constitución, la teoría de los principios jurídicos, la fuerza normativa de los precedentes judiciales, etc., son algunos ejemplos de esos cambios. Conceptos como los de jurisdicción, decisión judicial, hecho jurídico procesal, prueba, cosa juzgada, demanda, mérito, ejecución, merecen ser revisitados y reformulados. Ya no es posible repetir, acríticamente, que la jurisdicción es la aplicación de la voluntad concreta de la ley, como afirmaba Chiovenda.

Pero no hubo apenas cambios en la teoría del derecho más recientemente. Las transformaciones del derecho positivo también imponen una pausada reflexión sobre el derecho procesal: la expansión de la consensualidad en el ámbito del derecho público, el desarrollo del derecho administrativo 
sancionador, la proliferación de las leyes que protegen personas vulnerables (niños, ancianos, deficientes físicos, etc.) y el perfeccionamiento de la tutela colectiva de derechos son algunos ejemplos. Ya no es posible repetir, acríticamente, muletillas doctrinarias como «el proceso es de interés público», «el proceso no es cosa de las partes», «el proceso sirve para alcanzar la justicia del caso concreto», etc.

Paralelamente a ello, la ciencia jurídica latinoamericana también pasa por un momento de profundas transformaciones. Estamos comenzando a liberarnos intelectualmente de los italianos y españoles, que forjaron nuestro pensamiento.

Muchos de nosotros hemos buscado comprender el pensamiento jurídico inglés y estadounidense, sea por la lectura y citación en nuestros textos de los juristas de esos países, sea por la publicación en lengua inglesa de nuestros ensayos, sea por la realización de estudios en las principales universidades americanas e inglesas, con LLM's PhD's y programas de visiting scholar. Con ello, ignoramos la tendencia «antianglosajona» que marcó las ciencias sociales latinoamericanas por mucho tiempo.

Además de ello, estamos estrechando nuestros propios lazos: muchos de nosotros hemos viajado por los países del cono sur, dando conferencias, asistiendo a clases, publicando ensayos; nuestros libros están siendo publicados en español y portugués. El Instituto Iberoamericano de Derecho Procesal se está fortaleciendo cada día más (la propia revista del Instituto fue reconfigurada, siguiendo los más altos parámetros internacionales para las publicaciones periódicas). Algunos de nosotros están optando por cursar maestrías y doctorados aquí en Sudamérica, en vez de ir hacia Europa (Renzo Cavani y Christian Delgado, por ejemplo, hicieron su maestría en Brasil). Este homenaje a mi persona, por cierto, confirma lo que estoy diciendo.

Ha llegado la hora, queridos colegas, de dar nuestra contribución.

$Y$, para ello, no podemos tener miedo de arriesgar. Debemos ser osados para construir nuestro propio pensamiento jurídico y, de ser el caso, romper con la tradición. Errores ciertamente se cometerán. Pero el equívoco es el precio que se paga por la autonomía intelectual y por el avance de la ciencia. $Y$ ese precio es barato.

Sigo, en este punto, lo que dice Souto ${ }^{2}$ uno de los mayores filósofos del derecho brasileño: las teorías que buscan «refugio contra el error» son, al final del día, idolatría de lo preestablecido y la consagración del inmovi-

2 Souto, José. Ciência feliz. São Paulo: Max Limonad, 2000; pp. 21 y 22. 
lismo intelectual; son fruto de la primacía de la obediencia en detrimento de la originalidad; sirven como antídoto contra la investigación profunda; son, por eso mismo, la negación de la cientificidad.

Tenemos, por tanto, que hacer la apología a la osadía y del error.

Este es el primer paso para la construcción de una ciencia procesal latinoamericana de alto nivel.

\section{UNA PALABRA A LOS ESTUDIANTES PERUANOS: LAS APOLOGÍAS DE LA REFLEXIÓN Y DE LA PREGUNTA}

No podría concluir mi discurso de agradecimiento sin dirigir una palabra al estudiante peruano.

Vivimos en un momento histórico curioso.

Nunca fue tan fácil acceder al conocimiento, así como jamás se produjo tanto conocimiento.

Las personas saben cada vez más sobre las cosas de la vida. Pero aunque sepan de muchas cosas, la impresión que tengo es que, de un modo general, todos saben un poco sobre cada una de ellas. La extensión es inmensa; la profundidad, sin embargo, es la misma de un plato.

Todos opinan, todos comentan, todos deciden. $Y$ todo inmediatamente. Las redes sociales pasaron a ser las ágoras y los tribunales contemporáneos. Todos hablan y opinan. Pero, como indagó el profesor Leandro Karnal, de la Universidad de Campinas, en Brasil, ¿cuántos efectivamente escuchan la opinión ajena? ¿Cuántos efectivamente leen la cantidad de informaciones y texto que circulan diariamente?

Pocos, muy pocos.

Pocos reflexionan, ponderan, silencian. La lectura exige tiempo; lectura rápida es un oxímoron, es una contradicción. Pensar exige calma. Pensar exige un cierto sufrimiento. Pensar duele. Pensar cansa. Pero el "pensar» es presupuesto del «opinar» y del «decidir». No es fácil decir esto en un tiempo en que, dos minutos después de un post en el Facebook, ya hay cien «likes»...

En los tiempos actuales, es preciso hacer la apología de la reflexión y del silencio. La reflexión en el derecho presupone que se parta de una premisa: el arte del derecho es la retórica. El arte de dominar el lenguaje, comunicándose de modo eficiente y persuasivo. Pero en el derecho no se puede tolerar cualquier retórica. 
La buena retórica, la retórica del bien, es el arte de conjugar ethos, pathos y logos; o sea, la tríade aristotélica.

Ethos: carácter, credibilidad.

Logos: conocimiento, técnica.

Pathos: pasión, emoción.

Si ustedes pretenden ser buenos profesionales, no hay cómo escapar:

- deben ser éticos, para tener credibilidad;

- deben estudiar, para tener conocimiento; y

- deben emocionarse, para que puedan emocionar y convencer.

La práctica jurídica, en todas sus dimensiones, es un ambiente propicio para la retórica nefasta. En muchos casos, prevalece la posición de quien no tiene la razón.

Hay siempre mucho pathos; en muchos casos hay ethos; no siempre hay logos. Quien habla más alto no siempre tiene la razón (demasiado pathos); los libros inmensos de lenguaje complejo no siempre son buenos (nuevamente, pathos en exceso); el padre o profesor catedrático no siempre tiene razón (demasiado ethos).

Es necesario aprender a valorizar la autoridad del argumento y no el argumento de la autoridad. «Denken is Danken»: pensar es agradecer, como dice Heidegger. Pensar no es obedecer.

El logos puede estar en la pregunta de un alumno, en la provocación de un lego, en la duda de un niño.

Las respuestas entorpecen; las preguntas traen siempre consigo el gen de la incerteza, de la iconoclastia, de la revolución.

iProvoquen! iPregunten! iCuestionen! iDuden!

He aquí la tercera apología: ila apología a la pregunta!

A partir de hoy, mi vida entra en una nueva fase. Por un lado, asumo formalmente un compromiso de mantener estrecho mi vínculo con el Perú; por otro, mi responsabilidad intelectual se multiplica.

No sé si tengo condiciones de cargar con esta responsabilidad, así como tampoco sé si merecía este homenaje.

La única certeza que tengo es que estoy muy honrado, feliz y conmovido. iMuchísimas gracias! 